Neutronics Assessments for a RIA Fragmentation Line Beam Dump Concept

J. L. Boles, S. Reyes, L. E. Ahle, W. Stein

May 16, 2005

2005 Particle Accelerator Conference

Knoxville, TN, United States

May 16, 2005 through May 20, 2005 
This document was prepared as an account of work sponsored by an agency of the United States Government. Neither the United States Government nor the University of California nor any of their employees, makes any warranty, express or implied, or assumes any legal liability or responsibility for the accuracy, completeness, or usefulness of any information, apparatus, product, or process disclosed, or represents that its use would not infringe privately owned rights. Reference herein to any specific commercial product, process, or service by trade name, trademark, manufacturer, or otherwise, does not necessarily constitute or imply its endorsement, recommendation, or favoring by the United States Government or the University of California. The views and opinions of authors expressed herein do not necessarily state or reflect those of the United States Government or the University of California, and shall not be used for advertising or product endorsement purposes. 


\title{
NEUTRONICS ASSESSMENTS FOR A RIA FRAGMENTATION LINE BEAM DUMP CONCEPT*
}

\author{
J. L. Boles ${ }^{\#}$, S. Reyes, L. E. Ahle, W. Stein, LLNL, Livermore, CA 94550, U.S.A.
}

\begin{abstract}
Heavy ion and radiation transport calculations are in progress for conceptual beam dump designs for the fragmentation line of the proposed Rare Isotope Accelerator (RIA). Using the computer code PHITS, a preliminary design of a motor-driven rotating wheel beam dump and adjacent downstream multipole has been modeled. Selected results of these calculations are given, including neutron and proton flux in the wheel, absorbed dose and displacements per atom in the hub materials, and heating from prompt radiation and from decay heat in the multipole.
\end{abstract}

\section{BEAM DUMP DESCRIPTION}

RIA is a proposed new accelerator facility to address emerging research opportunities in low energy nuclear physics, and the Office of Nuclear Physics (NP), Office of Science (SC), U.S. Department of Energy (DOE) is sponsoring pre-conceptual R\&D activities on the facility. In the fragmentation line of RIA, $400 \mathrm{~kW}$ of a heavy ion beam such as uranium will impact a light-element target such as lithium, producing a spectrum of fragmentation products. The unreacted primary beam and unwanted fragments will be spatially separated from the fragment of interest in the first dipole following the target and then impact a beam dump. Approximately 20 to $30 \%$ of the $400 \mathrm{~kW}$ of primary beam will be deposited in the production target, with the remainder to be deposited in the beam dump. The beam dump will be designed to be movable to accommodate different primary beam species.

In collaboration with MSU, ORNL, LBNL, and ANL, several possible beam dump designs have been studied. One conceptual beam dump design evaluated is a $2 \mathrm{~m}$ diameter rotating wheel with a thin aluminum window. The primary beam traverses the window on the front face of the wheel and is stopped by water flowing through the wheel.

A simplistic model of the wheel dump and the downstream multipole, shown in Fig. 1, was created using the computer code PHITS [1]. The PHITS code is one of the first general-purpose heavy ion transport Monte Carlo codes applicable to energies from several $\mathrm{MeV} /$ nucleon to several $\mathrm{GeV} /$ nucleon. The model of the wheel dump consists of water inside an aluminum wheel, water spokes, and a hub region containing representative materials. The model of the multipole consists of annular cylinders of iron, copper, and iron; the copper cylinder was divided to include a region directly in line with the primary beam for tally purposes. The beam hitting the beam dump was $320 \mathrm{MeV} /$ nucleon uranium, $320 \mathrm{~kW}$, uniformly distributed with a circular cross section of $5 \mathrm{~cm}$ diameter, positioned $40 \mathrm{~cm}$ from the multipole centerline. The position of the beam dump was chosen since it represents the worst case for the dose rate received by the coils of the multipole.

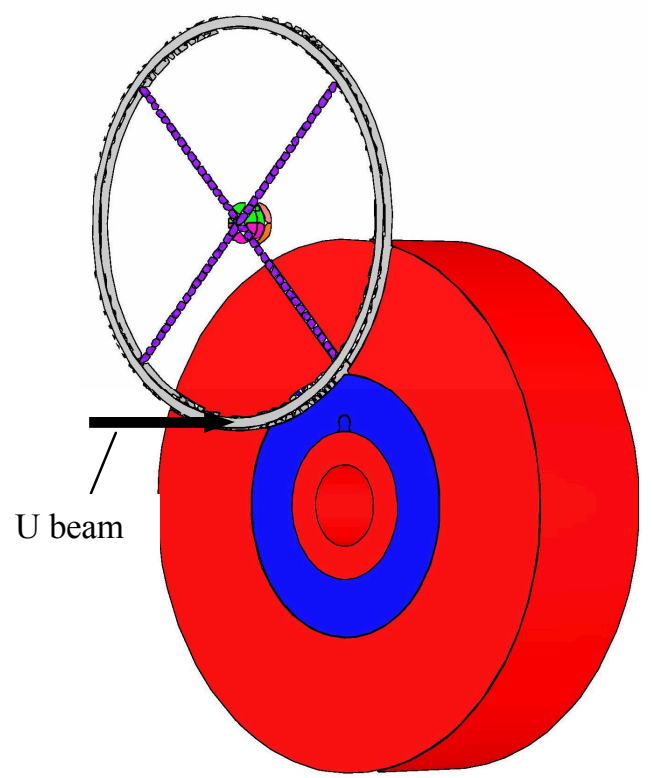

Figure 1. Geometry of wheel beam dump and multipole as modeled in PHITS.

\section{CALCULATED RESULTS}

The neutron flux averaged over the water volume in the wheel shows a peak in the $0-10 \mathrm{MeV}$ energy group, a broad plateau from about 10 to $300 \mathrm{MeV}$, and a steady decrease from about 300 to $700 \mathrm{MeV}$, beyond which the statistical uncertainties in the Monte Carlo calculated results were poor, exceeding $20 \%$. The proton flux showed the same general shape, except that the flux in the $0-10 \mathrm{MeV}$ energy group was lower than the flux in the $10-300 \mathrm{MeV}$ plateau. The neutron and proton fluxes are shown in Fig. 2.

Absorbed dose from prompt radiation was calculated for the following representative hub materials: Kapton polyimide film, samarium cobalt and neodymium iron boron magnets, and ferrofluid, as shown in Table 1. Assuming the fragmentation line is operating at the equivalent of full power for one-third of the year, the absorbed dose to the neodymium iron boron magnet exceeds its recommended dose limit of $0.1 \mathrm{MGy}$ in less than a year. Changing the position of the beam (and the

\footnotetext{
* Work performed under the auspices of the U. S. Department of Energy by University of California Lawrence Livermore National Laboratory under Contract W-7405-Eng-48.

"boles1@1lnl.gov
} 
beam dump) to $20 \mathrm{~cm}$ from the multipole centerline, equal to the inner radius of the multipole, resulted in reduced dose due to less neutron backscatter off the multipole.

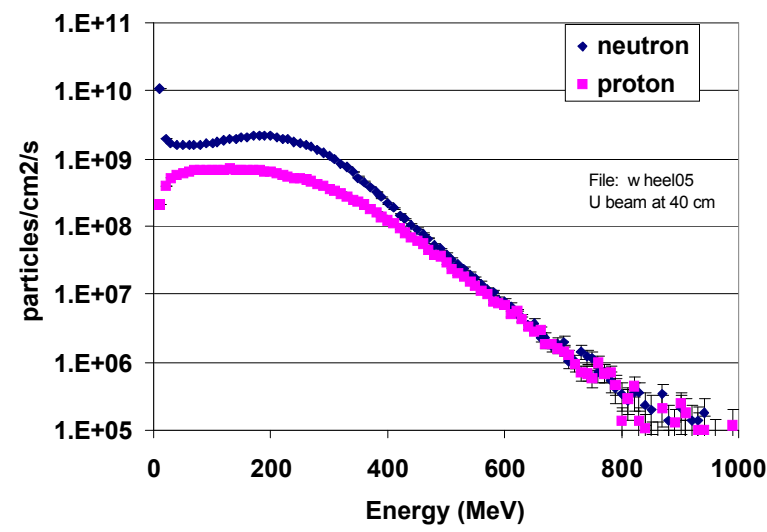

Figure 2. Neutron and proton flux in the wheel.

Table 1. Absorbed Dose in hub materials from prompt radiation

\begin{tabular}{|c|c|c|c|c|c|}
\hline \multirow[t]{2}{*}{ Material } & \multicolumn{2}{|c|}{ Beam at $20 \mathrm{~cm}$} & \multicolumn{2}{|c|}{ Beam at $40 \mathrm{~cm}$} & \multirow{2}{*}{$\begin{array}{l}\text { Limit } \\
\text { (MGy) }\end{array}$} \\
\hline & $\begin{array}{c}\text { MGy/ } \\
\mathrm{yr}^{*}\end{array}$ & $\begin{array}{c}\% \\
\text { neutron }\end{array}$ & $\begin{array}{c}\text { MGy/ } \\
\text { yr * }\end{array}$ & $\begin{array}{c}\% \\
\text { neutron }\end{array}$ & \\
\hline NdFeB & 0.16 & $52 \%$ & 0.32 & $83 \%$ & 0.1 \\
\hline SmCo & 0.054 & $57 \%$ & 0.14 & $88 \%$ & 100 \\
\hline Kapton & 0.52 & $59 \%$ & 0.67 & $62 \%$ & 10 \\
\hline FerroFluid & 0.54 & $85 \%$ & 0.68 & $90 \%$ & $>1 ?$ \\
\hline
\end{tabular}

* Assumes operational for $1 / 3$ of each year.

Displacements per atom in the hub materials were calculated and found to be negligible, as shown in Table 2. Displacements per atom in the wheel's front face are expected to be low, because most of the primary beam's energy is deposited in the water inside the wheel.

Table 2. Displacements per atom in hub materials

\begin{tabular}{|c|c|c|c|c|c|}
\hline \multirow[t]{2}{*}{ Material } & \multirow{2}{*}{$\begin{array}{l}\text { Density } \\
(\mathrm{g} / \mathrm{cc})\end{array}$} & \multicolumn{2}{|c|}{ Beam at $20 \mathrm{~cm}$} & \multicolumn{2}{|c|}{ Beam at $40 \mathrm{~cm}$} \\
\hline & & $\begin{array}{l}\text { DPA/ } \\
\text { yr * }\end{array}$ & $\begin{array}{c}\% \\
\text { neutron }\end{array}$ & $\begin{array}{c}\text { DPA/ } \\
\text { yr * }\end{array}$ & $\begin{array}{c}\% \\
\text { neutron }\end{array}$ \\
\hline $\mathrm{NdFeB}$ & 6 & $2.4 \mathrm{E}-6$ & $95 \%$ & $2.5 \mathrm{E}-6$ & $99 \%$ \\
\hline SmCo & 8.82 & $2.3 \mathrm{E}-6$ & $99 \%$ & $2.2 \mathrm{E}-6$ & $100 \%$ \\
\hline Kapton & 1.42 & $5.4 \mathrm{E}-7$ & $95 \%$ & $7.7 \mathrm{E}-7$ & $99 \%$ \\
\hline FerroFluid & 1.42 & $2.3 \mathrm{E}-7$ & $99 \%$ & $2.2 \mathrm{E}-7$ & $99 \%$ \\
\hline
\end{tabular}

* Assumes operational for $1 / 3$ of each year.

Calculations of the activation of water in the beam dump are in progress.

Heat deposited in the multipole from prompt radiation was calculated for a small region directly in line with the primary beam in $1 \mathrm{~cm}$ increments axially and $0.5 \mathrm{~cm}$ increments radially. A peak energy deposition of $0.07 \mathrm{~W} / \mathrm{g}$ was calculated, corresponding to a peak absorbed dose of $0.25 \mathrm{MGy} / \mathrm{h}$. A total of $4.7 \mathrm{~kW}$ was deposited in all regions of the multipole. Figure 3 shows the heat deposition as a function of depth into the multipole for a circular region of radius $0.5 \mathrm{~cm}$ positioned $40 \mathrm{~cm}$ from the multipole centerline.

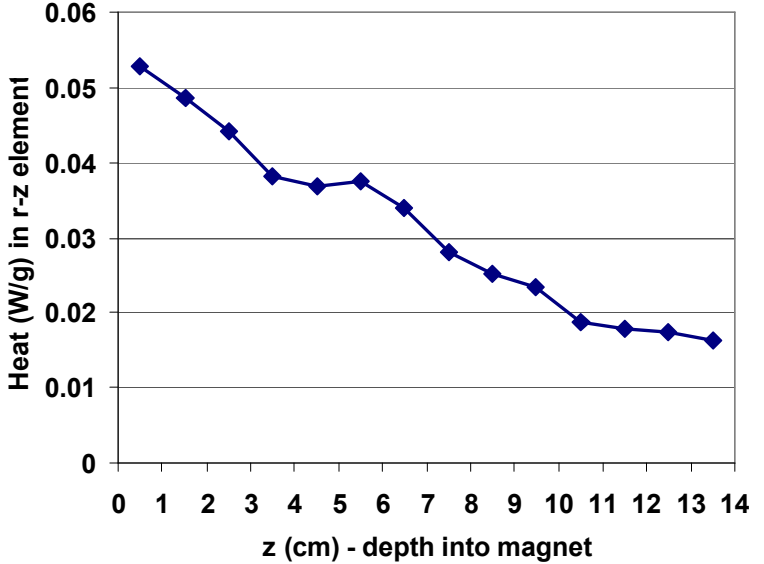

Figure 3. Heat from prompt radiation in a small region of the multipole.

Decay heat from radionuclides produced in the multipole was also calculated, considering both high energy $(>20 \mathrm{MeV})$ and low energy $(<20 \mathrm{MeV})$ activation. Low energy activation was calculated by exporting the neutron flux to the ACAB activation code [2]. Figure 4 shows the decay heat in a small region of the multipole (a cylinder of radius $0.5 \mathrm{~cm}$, length $1 \mathrm{~cm}$, positioned in line with the primary beam $40 \mathrm{~cm}$ from the beam centerline) as a function of time after operation for 28 days of a $320 \mathrm{~kW}$ uranium beam hitting the beam dump.

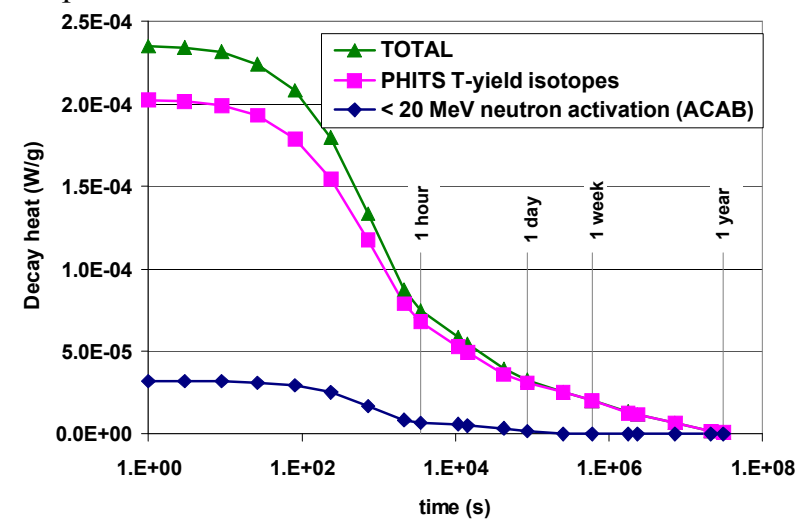

Figure 4. Decay heat from a small region of the multipole.

Displacements per atom in the multipole was calculated and found to be low, 0.02 DPA per operational year.

\section{CONCLUSIONS}

Heavy ion and radiation transport calculations using the computer code PHITS are ongoing for conceptual beam dump designs for the fragmentation line of the proposed RIA. For a $2 \mathrm{~m}$ diameter wheel beam dump concept, with the beam positioned at a worst case of $40 \mathrm{~cm}$ from the multipole centerline, calculations show that the absorbed dose to the neodymium iron boron magnet in the hub of the wheel exceeds its recommended dose limit of $0.1 \mathrm{MGy}$ in less than a year. Potential shields around the 
hub region could be considered to extend the life of this component. Heat deposition from prompt radiation in the multipole may be significant, whereas damage in the wheel and in the multipole from atomic displacements is not. Although further calculations are needed, it appears that this beam dump concept is feasible.

\section{REFERENCES}

[1] H. Iwase, K. Niita, and T. Nakamura, "Development of General-Purpose Particle and Heavy Ion Transport Monte Carlo Code," J. Nucl. Sci. Technol. 39 (2002) 1142.

[2] J. Sanz, ACAB Activation Code for Fusion Applications: User's Manual V5.0, UCRL-MA143238, Lawrence Livermore National Laboratory, Livermore, California, 2000. 